\title{
El Castillo de Bairén (Gandía, España). Proyecto de documentación gráfica
}

Bairén Castle (Gandía, Spain). Graphic documentation project

\author{
Pablo Rodríguez-Navarro ${ }^{\text {a }}$, Teresa Gil-Piqueras ${ }^{\text {b }}$ \\ Universitat Politècnica de València, Valencia, Spain \\ a rodriguez@upv.es; ${ }^{\mathrm{b}}$ tgil@ega.upv.es
}

\begin{abstract}
Bairén Castle was built in the Almoravid period, carring out the function of border hisn of the Taifa of Dénia. It was the administrative, political and legal-religious center of more than 20 farmhouses or qurà and castles. At present is possible visit the castle, although only part of its walls and remains of ruins scattered throughout the hill remain. The abandonment that has been suffering during these last years, together with the uncontrolled growth of the vegetation, make necessary to carry out urgent actions to conserve and put it in value. Within the framework of the study carried out in the initial phase of the Project for the authorization of the archaeological park of the castle of Bairén1, we have been developing an important work of graphic documentation, which will serve both to demonstrate the current state of the castle, as well as for the archaeological and restoration works. The main objective of this communication is to set the methodology for the graphic survey according to this type of monuments, establish the workflow, and finally, show the graphic documentation obtained.
\end{abstract}

Keywords: Bairen, castle, Almoravide, photogrammetry.

\section{Introducción}

El Castillo de Bairén o Bayrén, declarado Bien de Interés Cultural (BIC), se encuentra en la provincia de Valencia, a $2,5 \mathrm{~km}$ al oeste del puerto de Gandía y a $3 \mathrm{~km}$ del centro urbano de esta localidad. Su ubicación en lo alto del cerro de San Juan, al este de la Sierra de Mondúver, a $108 \mathrm{~m}$ de altitud sobre el nivel del mar, y frente a los humedales de la Safor, lo sitúan en una posición geoestratégica preferente para el control tanto marítimo como terrestre. Desde su ubicación se domina visualmente el frente litoral, desde el Cabo de Cullera hasta el Montgó en Denia, así como parte del área fluvial del río Serpis.

En época Romana junto a Bairén discurrió la vía de comunicación que unía Valentia (Valencia) y
Dianium (Dénia) pasando por Portum Sucrone (Cullera). Esta vía, que formaba parte de la red secundaria de caminos de la vía Augusta, se ha mantenido en el tiempo, dando hoy en día lugar a la actual red de carreteras (Ruiz Server, Vercher Navarro, 2012).

Tras las prospecciones arqueológicas llevadas a cabo en 1994, a petición del Excmo. Ayuntamiento de Gandía para la fase de documentación previa al Proyecto de actuación integral sobre Bairén, se determinó que en el área que hoy en día ocupa el castillo hay constancia de presencia humana desde la Edad del Bronce, siendo en época Medieval Islámica, cuando se usa el lugar 
como asentamiento militar, además de como hábitat (Castella, et al., 1994, p. 73).

En agosto de 2018, el castillo de Bairén recibió una subvención de la Generalitat Valenciana en cofinanciación con el Programa Operativo FEDER de la Comunidad Valenciana 2014-2020, destinada a la financiación de proyectos locales dirigidos a la "protección, conservación o recuperación de bienes patrimoniales culturales valencianos". Bajo el marco del estudio realizado en la fase inicial del Proyecto de habilitación del parque arqueológico del castillo de Bairén ${ }^{l}$, hemos venido elaborando una importante documentación gráfica, que servirá tanto para documentar el estado actual de castillo, como de base para los trabajos arqueológicos y de restauración, y que pretende evolucionar a media que avancen dichos trabajos, documentando su proceso.

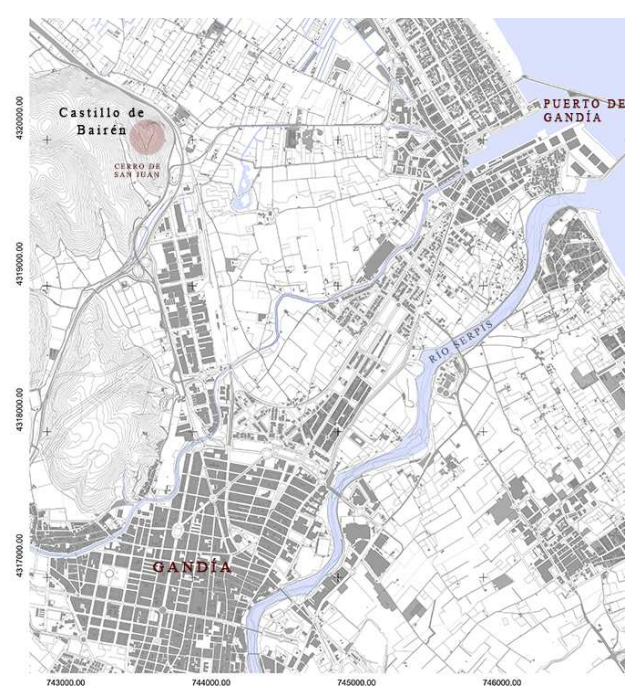

Fig. 1. Imagen del castillo de Bairén sobre la sierra de Mondúver. Localización a partir de coordenadas UTM: 743.709,40m. E, 4.320.047,74m. N, huso 30S.

\section{Breve recorrido histórico del castillo de Bairén}

El Castillo de Bairén data del siglo XI, aunque se han encontrado restos cerámicos de época $\mathrm{Ca}-$ lifal que lo sitúan en el siglo X (Castella, et al., 1994, p. 72).
La primera referencia escrita sobre el castillo aparece en un manuscrito anónimo del siglo XII en el que se narra la crónica Historia Roderici (Gómez Bayarri, 2008, p. 160). En ella se cuenta la batalla sucedida en 1097 a los pies de Bairén entre las tropas almorávides de Muhammad ibn Texufín y el ejército de Rodrigo Díaz de Vivar (El Cid) ayudado por las tropas aliadas de Pedro I de Aragón. Del siglo XII es también la crónica del geógrafo Abū Abdallah Muḥammad al-Idrīsī, en la que sitúa la ubicación del castillo entre las poblaciones de Xátiva, Orba, Dénia y Cullera (Sánchez i Signes, 2010, p. 138).

Durante la época Medieval Islámica, el castillo de Bairén cumplió la función de hisn ${ }^{2}$ de frontera de la Taifa de Dénia, además de ser el centro administrativo, político y jurídico-religioso de más de 20 alquerías o qurà, y de actuar como núcleo principal de la red de castillos de la comarca, entre los que se encontraban: Alfàndec (Benifairó de la Valldigna), Vilella (Almiserà), Borró (Ròtova), Palma (Alfauir), Rebollet (Font d'En Carròs), i Vilallonga (Vilallonga) entre otros (Bazzana, 1983), (Sánchez i Signes, 2010).

Durante los siglos XI al XIII aparece citado en numerosas fuentes documentales islámicas afirmando su importancia socioeconómica, militar y defensiva (Sánchez i Signes, 2010, p. 138).

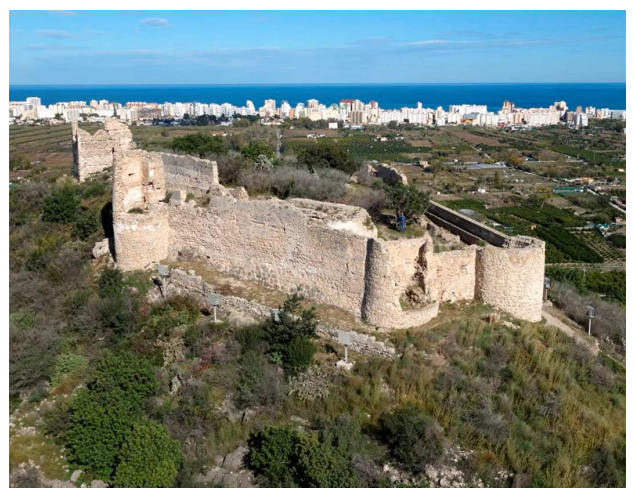

Fig. 2. Vista aérea del castillo. Al fondo los humedales y la playa de Gandía (Rodríguez\&Gil).

En el año 1239 el castillo es conquistado por el ejército de Jaime I, y aparecen las primeras referencias cristinas sobre Bairén (Gómez Bayarri, 
2008, p. 160). En la Crónica que redacta el rey Jaime I sobre la conquista de Valencia, recogida en el Libre del Feyts, son diversas las referencias que el monarca hace al castillo. De ellas se deduce que en esa época el castillo estaba ocupado y gobernado por un alcaide:

"Entram en la Val de Bayren e parlam en l'alcayt que tenia lo Castell."

En el texto también documenta la importancia del castillo respecto al resto de fortificaciones vecinas, cuando dice que de su rendición depende la rendición del resto de castillos:

"307. E quan aço fo passat entram en la Ual de Bayren, e de Borro, e de Villela e de Palma, qui eren castells de rocha grans e forts. E dixeren nos que quan lalcait de Bayren hauria feit pleit ab nos, que tots aquels de la ual se rendrien."

Tras vencer a los musulmanes, Jaime I pactó con Abecendrel la entrega del castillo, prometiendo respetar campos y cosechas, pasando el control militar a manos cristianas (Gómez Bayarri, 2008, p. 161), tal y como figura en el Llibre del Repartiment. Durante esta época Bairén controla la franja litoral entre el río Serpis y el de San Nicolás, hasta que se funda la Vila de Gandía en el siglo XIII (Sánchez i Signes, 2010).

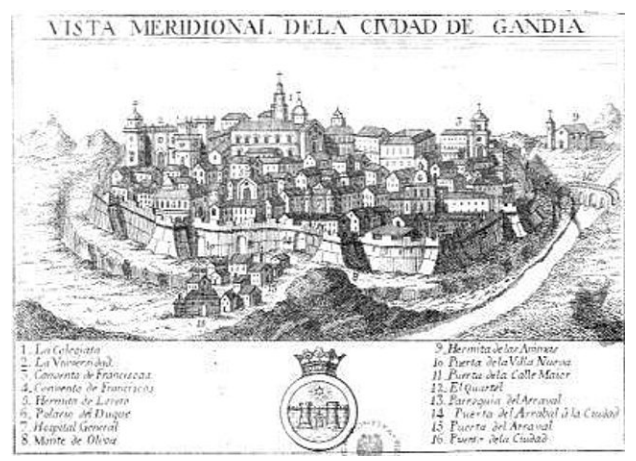

Fig. 3. Vista de la ciudad de Gandía en el siglo XVIII, según Juan Fernando Palomino (Gandía (Valencia) Vistas de ciudades 1786, Biblioteca Digital Hispánica).

Con la fundación de la Vila de Gandía (Fig. 3) sobre la planicie litoral, al sur del cerro de San Juan, la población de Bairén pasa poco a poco a habitar dicha planicie, abandonando la colina. Durante el siglo XIV, el castillo sólo mantiene su función militar, debido a su posición geoestratégica.

En 1399 el rey Martín I de Aragón, conocido también como Martín el Humano, nombrará primer duque de Gandía a Alfonso el Viejo, época en la que se construirá la ermita de San Juan dentro de la qasaba. La población abandonará definitivamente el área del castillo, que permanecerá sólo como asentamiento militar hasta el siglo XVI según indican las investigaciones arqueológicas llevadas a cabo en 1994, que sitúan restos cerámicos en época Medieval Cristina hasta este siglo (Castella, et al., 1994, p. 72).

\section{Morfología del castillo de Bairén}

El castillo de Bairén sigue la tipología de las fortalezas de Sharq al-Ándalus. Su estructura está formada por tres anillos que crecen en superficie a medida que descendemos la montaña. Estas tres estructuras son: la qasaba en la parte superior, seguida del recinto delimitado por el albacar, y finalmente bajo estos dos se situaría la madīna (Fig. 4).

De la madina, situada posiblemente en la vertiente oriental y nororiental de la colina (Ruiz Server, Vercher Navarro, 2012) no quedan indicios visibles, más allá de algún que otro resto que podría atribuirse a alguna de sus subestructuras. Esta zona estaría rodeada por una muralla y dentro de ella la población habitaría de forma permanente. Tras la conquista cristiana en 1239 pasará a conocerse como la Vila cristina de Bairén, aunque por poco tiempo, ya que sus pobladores acabarán incorporándose a la Vila de Gandía, situada en la planicie.

A medida que subimos el cerro por el camino situado al oeste del castillo, el primer recinto que encontramos es el albacar. En los restos de los muros se aprecia el paso de la entrada original. Bajo la protección del albacar buscaba refugio la población de las alquerías vecinas y sus animales, cuando se producían ataques en la zona.

El albacar ocupa una superficie aproximada de $10840 \mathrm{~m}^{2}$ y tiene una planta sensiblemente triangular. Tras las últimas operaciones de limpieza, necesarias para la realización del levanta- 
miento gráfico, ha salido a la luz en su parte occidental una gran cantidad de lienzos de muralla y torres cilíndricas, que han puesto aún más en valor este conjunto.

Por último, en la parte alta del castillo, encontramos la qasaba, en la que se situaría una guarnición militar y los máximos representantes del castillo. Su superficie actual aproximada es de $2350 \mathrm{~m}^{2}$. De la qasaba quedan restos de la mayor parte del perímetro de su muralla y de la torre del homenaje, así como de la antigua puerta, rematada por dos torres de planta circular, hoy en día tapiada tras su restauración. En su interior encontramos un aljibe y diversas estructuras, posiblemente correspondientes a estancias.

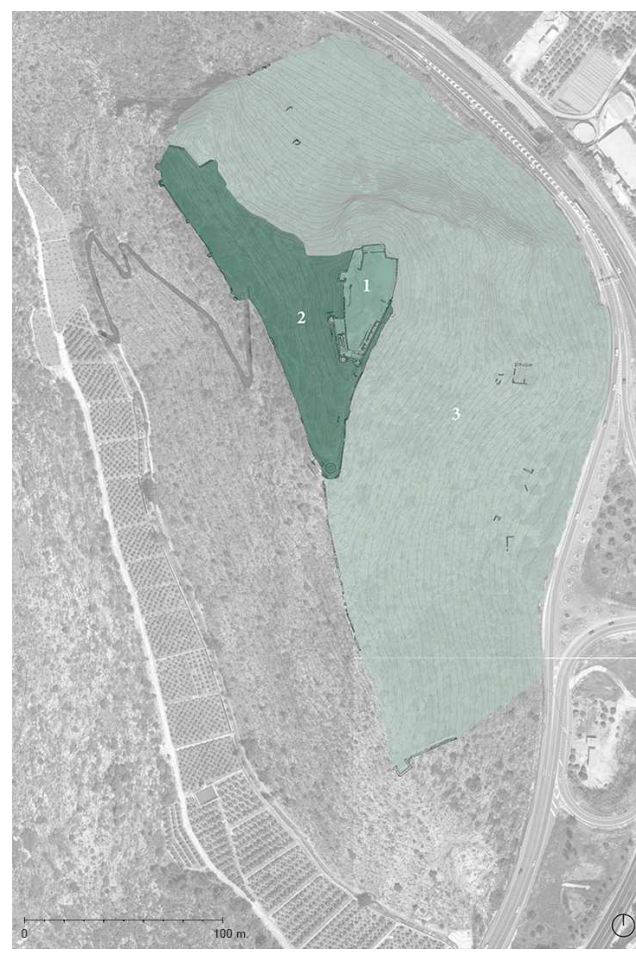

Fig. 4. Estructura del castillo de Bairén sobre ortofotografía. 1) Qasaba; 2) Albacar; 3) Madina (Rodríguez\&Gil).

En la actualidad, a la qasaba se accede por una única puerta (Fig. 5) rematada por un arco de piedra de medio punto, que se sitúa más o menos en la mitad de su lienzo oriental. Desde ella se accede a una gran explanada, desde la que a su vez se articulan diferentes estructuras y caminos.

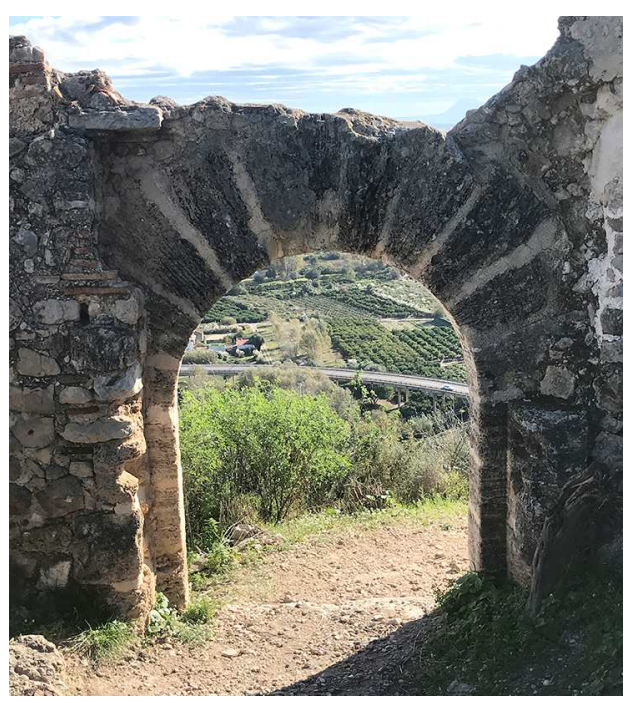

Fig. 5. Vista interior de la actual puerta de acceso a la qasaba (Rodríguez\&Gil).

En los últimos 25 años el castillo ha vivido diversas actuaciones, como la intervención auspiciada por la Casa de Oficios (1997) o la del Plan Director de Actuaciones del Castillo de Bairen (1998) redactado por el arquitecto J. M. Climent y la arqueóloga J. Cardona, aunque no han sido las únicas. El avance del tiempo y las constantes remodelaciones sufridas en época cristiana hacen que hoy en día sea muy difícil determinar la estructura original del castillo, sin la realización de una campaña arqueológica previa.

\section{Levantamiento gráfico del castillo}

Siguiendo la Carta del Restauro de 1972, redactada por Cesare Brandi en 1988, podemos leer "El proyecto se basará en un completo levantamiento planimétrico y fotográfico, interpretado también bajo el aspecto metrológico, de los trazados reguladores y de los sistemas proporcionales, $[\ldots] "$.

Hoy en día, dicho proyecto de levantamiento se basa en la digitalización completa del lugar, del edificio, del objeto, que nos permitirá interrogarlo, estudiarlo, seccionarlo, compararlo, analizarlo, reproducirlo, y darle tantos otros usos como 
se desee; incluso algunos usos que no será necesario desarrollarlos en el momento, pero que a buen seguro serán posibles en el futuro gracias a la adquisición de los datos reales, precisos y fiables, obtenidos directamente del modelo original. En este sentido el conocimiento de las diferentes técnicas de levantamiento digital nos permite adaptar la metodología del levantamiento a las necesidades tanto del modelo a representar, como del proyecto que se pretende llevar acabo, optimizando así los resultados.

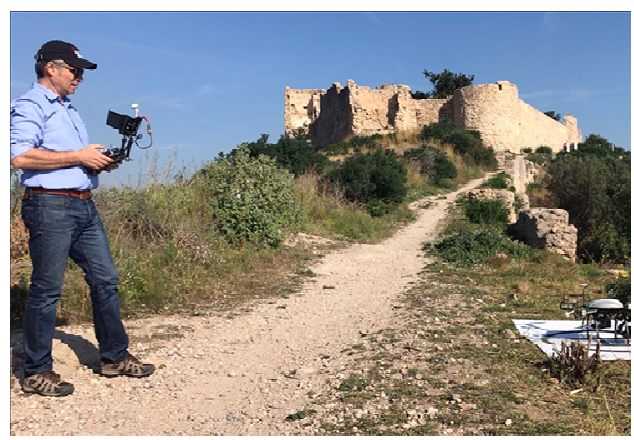

Fig. 6. Toma de datos del castillo a través de vuelo con dron (Rodríguez\&Gil).

Según la declaración sobre el levantamiento arquitectónico de Roma en 2000, "el levantamiento arquitectónico es un proceso de investigación enfocado hacia el conocimiento de la arquitectura o de la ciudad; como toda investigación requiere ir precedido del proyecto de levantamiento, es decir, la planificación de las acciones a cumplir [...]" (Almagro, 2004).

De este modo, las primeras actuaciones sobre el Castillo de Bairén fueron el estudio de las particularidades del lugar, junto con las necesidades planteadas por los técnicos redactores del proyecto de conservación. Tras la visita se observó la dificultad de la toma de datos, debida fundamentalmente a:

- La gran dimensión del castillo, con construcciones en sus tres áreas, y con la necesidad de obtener también un levantamiento del terreno.

- La inaccesibilidad a muchos de sus cerramientos, ya sea por la vegetación, como por su construcción sobre acantilados inaccesibles.
- La gran presencia de cal en muchas de sus fábricas, lo que, en días soleados, provoca un desequilibrio lumínico entre las zonas reflectantes y otras en sombra, que dificultan las tomas fotográficas de calidad suficiente para su uso en la fotogrametría.

Por otro lado, el castillo no presenta construcciones cubiertas o enterradas, estando todas sus estructuras visibles.

Tras el análisis de estos condicionantes, y tras la preceptiva limpieza de la vegetación, determinamos que el levantamiento se realizaría por medio de fotogrametría, realizando las tomas fotográficas tanto en un recorrido a pie en las zonas accesibles, como mediante el vuelo de un dron (Fig. 6). Por otro lado, se hace necesario la colocación de dianas repartidas en su superficie para realizar un apoyo topográfico que garantice la exactitud del levantamiento, debido a su gran magnitud en superficie. Tras dicho apoyo se realizaron un total de 1689 fotografías, divididas en tres secciones. Una primera corresponde a un vuelo programado del dron para realizar fotogramas perpendiculares al terreno, al objeto de obtener un modelo completo del área de estudio. La segunda se corresponde con la colección de fotografías realizadas para completar las construcciones murarias en sus paramentos verticales, realizando tomas a $45^{\text {a }}$ desde el dron y horizontales a mano. La tercera colección comprende la toma de aquellos paramentos de pequeños espacios que no pueden ser fotografiados desde varios puntos de vista, y que deben ser resueltos con una única fotografía.

\subsection{Sistemas de levantamiento}

Para la obtención del modelo 3D y de los fotoplanos se utilizaron dos sistemas fotogramétricos: la rectificación y la restitución.

- Rectificación fotogramétrica (2D): parte de una única fotografía del objeto y basándose en unas medidas tomadas con estación total, que nos definen un plano contenido en ella, ajusta dicha imagen hasta obtener una vista ortogonal y métrica de dicho plano, sobre la que podremos dibujar a escala. El flujo de trabajo es el siguiente: calibración de la cámara fotográfica, determinación de puntos singulares (dianas o puntos mor- 
fológicos), obtención de las coordenadas (x,y,z) de los puntos singulares, toma de la fotografía, corrección (eliminación de la deformación esférica), rectificación (imagen diédrica). La imagen rectificada se editará con Photoshop para eliminar todos aquellos elementos que no se encuentren en el plano rectificado. Posteriormente se inserta en Autocad y se escalar según las propias coordenadas obtenidas de los puntos singulares.

Este sistema sólo podrá ser de aplicación en los elementos arquitectónicos planos, es decir, contenidos en una superficie sensiblemente plana.

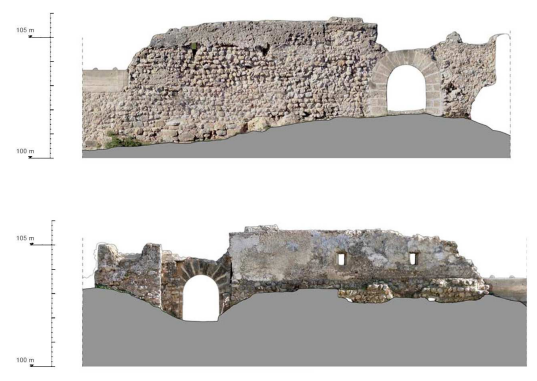

Fig. 7. Alzado fotogramétrico del lienzo oriental de muralla de la qasaba, en donde se sitúa la actual entrada (Rodríguez\&Gil).

- Restitución fotogramétrica (3D): sin embargo, existen muchos elementos que no responden a la condición de planeidad requerida para la rectificación, e incluso abundantes casos en los que la fábrica tiene un mortero altamente erosionado, lo que hace que su superficie no sea lo suficientemente plana, necesitando un sistema de obtención de fotoplanos basado en la restitución 3D. Además, la comodidad y fiabilidad que otorga la digitalización del objeto en un único modelo 3D, otorga un mayor control sobre su ajuste, al tiempo que garantiza una mayor precisión global.

Dentro de los sistemas existentes para la restitución fotogramétrica se ha utilizado el denominado SfM (Structure from Motion), que se basa en la toma de una secuencia fotográfica de un objeto, para de forma semi-automática y bajo los parámetros marcados por el operador, crear un modelo que incluye la orientación de las imágenes, obtención de la nube de puntos con información RGB, la generación de mallas poligonales y la inclusión de texturas fotorrealísticas. $\mathrm{La}$ alta precisión del sistema (Doneus, et al., 2011) y la baja desviación existente frente a los modelos obtenidos a partir de datos provenientes de escáneres láser ya han quedado demostradas (Rodríguez-Navarro, 2012).

Con el modelo tridimensional texturizado (https://skfb.ly/6IWZz) se procedió a la realización de los cortes siguiendo las localizaciones indicadas en el análisis de vistas necesarias consensuadas con los técnicos redactores del proyecto de conservación. La resolución de las imágenes obtenidas en dichos cortes ha sido siempre superior a la escala máxima de los planos, llegando a aquella necesaria para la correcta lectura y posterior delineación e interpretación de la estratigrafía muraria y de las lesiones.

$\mathrm{Al}$ igual que las imágenes obtenidas por medio de rectificación, las imágenes se editan con Photoshop para eliminar todos aquellos elementos que no se encuentren en el fotoplano, a continuación, la ortofoto se inserta en Autocad y se escala según las referencias generales en planta, obtenidas mediante el levantamiento con estación total topográfica.

\subsection{Equipos empleados}

Los equipos utilizados en el proceso de documentación y toma de datos para el levantamiento gráfico han sido los siguientes:

a) Estación topográfica: para el apoyo topográfico del levantamiento se utilizó una estación total robótica, modelo Imagen IS, de la marca Topcon. Esta estación tiene una capacidad de medición con prisma de $3000 \mathrm{~m}$ con una precisión de $\pm 2 \mathrm{~mm}+2 \mathrm{ppm} \times \mathrm{D}^{*}$ m.s.e.

b) Dron profesional: para la realización de fotografías aéreas, tanto de entorno como necesarias para el levantamiento fotogramétrico, se utilizó un dron Quad fabricado por Dronetools. Sus características principales son:

- Chasis de carbono con cuatro brazos plegables.

- Cuatro motores eléctricos tipo brushless AXi $2820 / 18$ de $555 \mathrm{~W}$ de potencia.

- Hélices de fibra de carbono huecas de 14 pulgadas de diámetro y 5 pulgadas de paso. 
- Control mediante sistema de piloto automático DJI A2.

- Montura de cámara de dos ejes (pan and tilt) en fibra de carbono, con motores brushless.

- Batería 6S 7000 mAh (autonomía de 20 a 30 minutos)

- Pesos: en vacío, 1700 gr; con una batería, 2607,5 gr; peso máximo al despegue (MTOW) 3800 gr.

c) Cámaras fotográficas: para garantizar la calidad en la fase fotográfica se utilizaron cámaras de última generación, con sensores de formato 1 " y completo (full frame) y lentes de alta calidad. A continuación, enumeramos las características de las cámaras empleadas:

- Cámara Sony RX100II para transportar con el dron, dotada con una resolución de 20,2 Mb, sensor CMOS de 13,2 x 8,8 mm y lente Carl ZEISS f1,8, de longitud focal equivalente 28 $100 \mathrm{~mm}$.
- Cámara Sony $\alpha 7 r$, con una resolución de 36,4 $\mathrm{Mb}$, sensor de formato completo, dotada de lente profesional Carl Zeiss para apoyo terrestre.

\section{Conclusiones}

Hemos presentado aquí los primeros resultados del proyecto de levantamiento gráfico del Castillo de Bairén. La metodología utilizada y sus flujos de trabajo, han sido eficaces para obtener un levantamiento integral. La fiabilidad global del modelo ha sido alta, corroborada por la mínima desviación con respecto a la nube del apoyo topográfico, desviaciones que han variado de 1 a 5 $\mathrm{cm}$ en un levantamiento que ha superado los 125 $\mathrm{m}$ en su lado mayor. Los datos fueron tomados en tres sesiones, dos de ellas de cinco horas, con la participación de un piloto de drones, un observador de ayuda al piloto y un operador de estación total, y una tercera sesión de una hora, para completar algunas lagunas detectadas y repetir
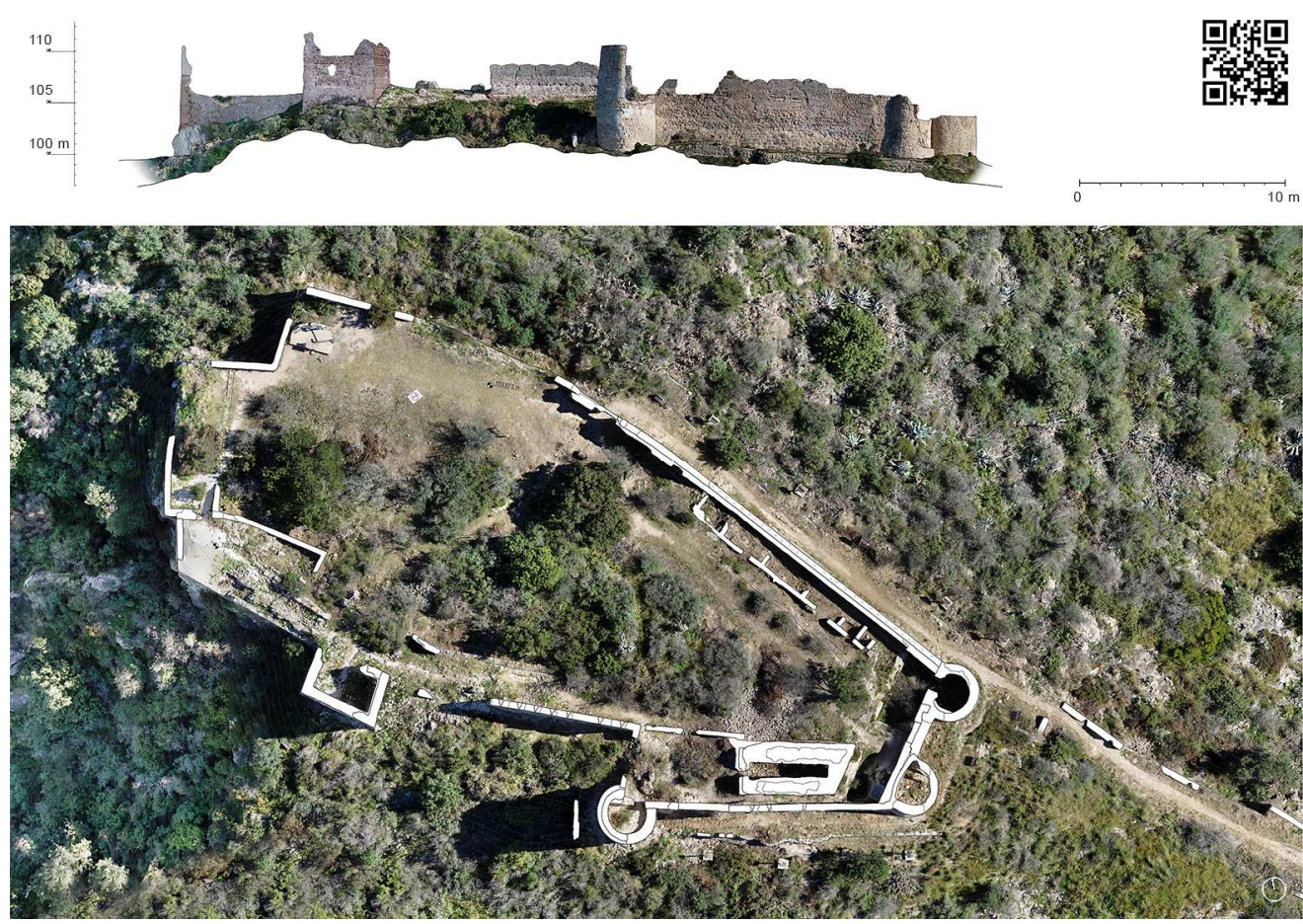

Fig. 8. Planta fotogramétrica de la qasaba y alzado oeste del castillo (Rodríguez\&Gil). 
fotografías que presentaban los esperados problemas lumínicos.

Los trabajos seguirán avanzando en paralelo a las sucesivas fases de la excavación arqueológica, teniendo intención de realizar secuencias estratigráficas tridimensionales (Martín Civantos, Romero Pellitero, 2017).

\section{Notas}

${ }^{1}$ El Proyecto de habilitación del parque arqueológico del castillo de Bairén, está dirigido por el arquitecto Fernando Mut Oltra. Dicho proyecto incluye El estudio Arquitectura y paisaje del castell de Bairen (Gandía): estudio, investigación y diagnóstico, coordinado por la arquitecta Dra. Alba Soler Estrela, de la Universitat Jaume I de Castellón. La fase de toma de datos y elaboración grafica de planos ha sido dirigida por los profesores Dr. Pablo Rodríguez-Navarro y Dra. Teresa Gil-Piqueras, de la Universitat Politècnica de Valencia. El equipo ha contado con el asesoramiento del Dr. arquitecto Rafael Soler Verdú y la supervisión del arquitecto Fernando Mut Oltra.

${ }^{2}$ Según Sánchez, un hisn es "un sitio castral hispanomusulmán con funciones diversas aparte de la militar, y que centraliza un poblamiento rural basado en una o más qurà que, junto a otras formas de asentamiento menores, unidas físicamente al castillo o dispersas por las tierras de cultivo de su 'amal, forman una alhama, un territorio autónomo por lo menos a finales del siglo XII y primeras décadas del XIII, con organismos propios basados en la organización familiar, de clanes y tribal" (Sánchez i Signes, 2010, p. 138).

\section{Bibliography}

Almagro Gorbea, A. (2004). Levantamiento arquitectónico, Universidad de Granada, Granada.

Bazzana, A. (1983). "El món islàmic”, in El llibre de la Safor, Sueca, pp. 249-256.

Bruguera, J., ed. (1991). Llibre dels Fets del rei Jaume I, Barcino Ed., Barcelona.

Castellá i Orengo, M.; Cloquell Estevan, S.; Ruiz Server, S.; Vercher Navarro, M. (1994). "Estudi del registre arqueolòcic superficial del Castell de Bairen Gandia, La Safor Valencia Castillo de Bairén”, in Alonso López, J.E., coord., Espai Obert, Revista d'Assaig i Investigacion, comarques Centrals Valencianes, Col.lectiu Espai Obert, Valencia.

Doneus, M.; Verhoeven, G.; Fera, M.; Briese, Ch.; Kucera, M.; Neubauer, W. (2011). "From deposit to point cloud A study oflow-cost computer vision approaches for the straightforward documentation of archaeological excavations", in 16 Conference on Cultural and New Technologies, Viena.

Gómez Bayarri, J.V. (2008). Castillos del camino del Cid en tierras valencianas, Real Academia de Cultura Valenciana, Valencia, pp. 158-162.

Martín Civantos, J.M.; Romero Pellitero, P. (2017). "From 3D to GIS. A comprehensive methodology for recording stratigraphy and its application in the MEMOLA Project”, DisegnareCON, 10, 19, pp. 2.1-2.16.

Rodríguez-Navarro, P. (2012). "Automated Digital photogrammetry versus the systems based on active 3D sensors La Fotogrametría Digital Automatizada frente a los sistemas basados en sensores 3D activos”, Revista EGA, 20, 2012, pp. 100-111.

Ruiz Server, S.; Vercher Navarro, M. (2012). El Castell de Bairén, Llibret Falla Plaça Sant Josep Raval.

Sánchez i Signes, M. (2010). "El recinte oriental del castell de Bairén (Gandia)", Recerques del Museu d'Alcoi, 19, pp. 137-156. 